\title{
Kyrgyz Lexicography in the 20th-21st Centuries
}

\author{
Mainisa Koshueva1, Elmira Abduvalieva² ${ }^{2}$ Akchach Zholdoshova ${ }^{3}$, Nazira Karaeva4, \\ Aigul Osmonova4, Riana Shaimkulova4, Gulzar Mamadieva4, Zhypargul Abdullaeva ${ }^{4 *}$
}

\author{
${ }^{1}$ Department of Kyrgyz Linguistics, Osh State University, Osh, Kyrgyzstan \\ ${ }^{2}$ Humanitarian Disciplines Cycle, Medical College, Kyrgyz-Uzbek University, Osh, Kyrgyzstan \\ ${ }^{3}$ Department of Psychology, Osh State University, Osh, Kyrgyzstan \\ ${ }^{4}$ Department of Kyrgyz Philology and Journalistic, Osh State University, Osh, Kyrgyzstan \\ ${ }^{5}$ Science and Research Department, Osh State University, Osh, Kyrgyzstan \\ Email: ^jypar.science@oshsu.kg
}

How to cite this paper: Koshueva, M., Abduvalieva, E., Zholdoshova, A., Karaeva, N., Osmonova, A., Shaimkulova, R., Mamadieva, G., \& Abdullaeva, Z. (2021). Kyrgyz Lexicography in the 20th-21st Centuries. Open Journal of Modern Linguistics, 11, 719-726.

https://doi.org/10.4236/ojml.2021.115057

Received: August 5, 2021

Accepted: September 11, 2021

Published: September 14, 2021

Copyright $\odot 2021$ by author(s) and Scientific Research Publishing Inc. This work is licensed under the Creative Commons Attribution International License (CC BY 4.0).

http://creativecommons.org/licenses/by/4.0/

\begin{abstract}
Works that directly contributed to the Kyrgyz lexicography formation are: Russian-Kyrgyz dictionary, spelling dictionary, dictionary of foreign words (Arabic, Iranian). In this article, development of lexical units, words and their interpretation, meanings in some phrases, etymological analysis of many words are considered. In this article, we are talking about the works of several scientists who made significant contribution to the Kyrgyz lexicography, dialectological works and encyclopedias published at present. A custom referred to generally accepted order, traditionally established rules in social behavior. It is a habitual way of action and behavior, a habit inherent in a social group (class, caste, nation, etc.), known to all its representatives, accepted and observed by people in their life. A custom is determined by the level of a society and culture development. The study of folkloristic culture begins precisely with the study of traditions and customs of particular ethnos.
\end{abstract}

\section{Keywords}

Etymological Studies, Phrasebooks, Kyrgyz-Russian Dictionary, Lexicographic Works, Reciprocal Words Dictionary, Dialectological Dictionary, Encyclopedic Dictionaries, Translation Dictionaries, Spelling Rules, Lexical Units

\section{Introduction}

In the Kyrgyz lexicography formation, the dictionaries were first translated from one language to another such are Kyrgyz-Russian, Russian-Kyrgyz dialogues, and published to learn the Russian language. The Russian literature multifaceted nature is important in the Kyrgyz school conditions, where this literature ap- 
pears not only as foreign language and foreign, but at the same time and as a part of culture in post-Soviet countries (Beisheev, 2018: p. 95). Currently in literature, the word lexicography used in the following meanings: 1) a special area of linguistic studying principles of composing different types of dictionaries; 2) practice of dictionaries construction; 3 ) a set of dictionaries in a given language (Dambuev, 2011: p. 16).

Transition of Russian words into Kyrgyz vocabulary began in the 1950s in the $19^{\text {th }}$ century before the October Revolution, from the day Kyrgyz people combined with Russia; before the appearance of mass literacy of Kyrgyz people, the words borrowed from Arab-Iranian languages and Russian words were subjected to phonetic deformation (Koshueva, 2021: p. 208).

Among such works, contributing to the Kyrgyz lexicography works by H. Karasaev were published in 1938 in Kazan, and the Russian-Kyrgyz dictionary was complemented by I.A. Batmanov. In the Kyrgyz language lexicography establishment, the works of the famous linguist-scientist H. Karasaev have a great influence; Kardashev's dictionary played an important role in the acquisition of the Russian language, the spread of linguistic science and education in the Kyrgyzstan. Therefore, H. Karasaev is considered as a great scientist of the Kyrgyz language, Kyrgyz words and the inner world of Kyrgyz people in general. K. Karasaev's great contribution to the development of Kyrgyz linguistics, especially lexicography was noted by his best personal psychological qualities, observations, creative thinking and Kyrgyz words knowledge.

In turn, the famous lexicographer K.K. Yudakhin "For a long time before Kyrgyz studies and before pre-revolutionary Kyrgyz culture, I also consider a thorough study of pre-revolutionary Kyrgyz writing and its language. On this topic, I have already begun to work together with my unchanging comrade H.K. Karasaev" he said. He also noted that the scientist was fluent in the language. K. Karasaev emphasizes, a great expert in Kyrgyz vocabulary, was my constant consultant (Yudakhin, 1965: p. 11).

Additional study of word meaning conveyed by adding consonants or syllables to the root words and played a large role in enriching the language vocabulary (Koshueva et al., 2020).

A custom is a multifaceted object of research of philosophers, historians, sociologists, ethnographers, representatives of jurisprudence, culturologists, politicians, linguists, and etc. Custom and tradition are close, mutually complementary concepts often used synonymously (Leontieva, 2014: p. 39).

Rationale in carrying this study based on lexigraphy researchers works and various kinds of dictionaries constructed by $\mathrm{K}$. Tynystanov, H. Karasaev, their contribution to Kyrgyz lexicography, linguo-ethnocultural lexicography etc. Current research work was focused on lexicography in XX centuries, because main archival works by K. Tynystanov who had contributed to the Kyrgyz lexicography establishment, H. Karasaev and K. Yudakhin from 1920 to 1930 years were analyzed and considered. 


\section{Research Methods}

In this work linguistic analysis (Rakhimova, 2014: p. 336), liguoculturological and humanitarian-euristic methods including taxonomic, explanatory description, generalization, characterization (Maslova, 2018: p. 173) analyses based on several linguist scientists works such are K. Karasaev, K. Yudakhin, S. Ibragimov, $\mathrm{H}$. Biyaliev and K. Tynystanov were used.

Research procedure is considering linguo-ethnocultural lexicography and $\mathrm{H}$. Karasaev's works, other works contribution to the Kyrgyz lexicography, dictionaries in the Kyrgyz lexicography, dialects and dialectical words, encyclopedic dictionaries role and $\mathrm{K}$. Tynystanov works.

\section{Results and Discussions}

\subsection{Linguo-Ethnocultural Lexicography and H. Karasaev's Works}

Consequently, the concept of "custom/adat" is a multi-faceted and multi-layered subject in research. The purpose of this section is to outline the basic ideas and principles of linguo-cognitology and linguo-ethnocultural studies, necessary for the study of the concept "custom/adat" in Russian and Kyrgyz linguocultures. "Ethno-linguistic consciousness is a cognitive-emotive and axiological structure in linguistics, providing their variability from one culture to another" (Abildinova, 2018: p. 39).

As it is well known, Kyrgyz linguistics has developed in the interdisciplinary scientific directions by educational and ethnocultural studies, linguo-ethnocultural studies, ethnocultural lexicography, united studied in the framework of applied philology, the purpose of which is to obtain a holistic understanding about applied philology as an emerging philological field and scientific discipline; mastering the theoretical (linguistic, literary) foundations of developing a methodology for setting and solving applied problems and conducting applied research in the most important spheres in human activity (Chuvakhin, 2012: p. 178).

Scientist H. K. Karasaev also published a large orthographic dictionary of the Kyrgyz language, which contains 60,000 words, as a result of many years of work on the development of Russian-Kyrgyz dictionaries, their collection, word collection, spelling. This work was published in several editions, as it made a significant contribution to the formation of the Kyrgyz literary language, outlining the correct spelling of words and word forms.

Also, well-known scientist S. Ibragimov, based on a new version of the spelling of the Kyrgyz language, developed by H. Biyaliev and others. A new edition of Karasaev's dictionary has been published as a result of his tireless work, a dictionary of words adapted from other languages in the Kyrgyz language was developed.

It can be seen that such dictionaries are the result of a scientist's determination, diligence, ingenuity and responsibility for his work. This work is a separate original work in the Kyrgyz lexicography, in particular containing a wide range of words from the Arabic and Iranian languages adapted into Kyrgyz language. 
From this point, it is possible to emphasize as an individual feature of the author, his ability to work at a high level of vocabulary through his extensive knowledge of the Arabic language.

H. K. Karasaev worked extensively not only on lexical units and words, but also on phraseologies and linguistic units with some special pronunciations. We know that he has created a number of books by collecting and analyzing phrases that have become common in the works of writers and folklore, paying special attention to metaphors. H. K. Karasaev works "Proverbs" (Karasaev, 1982), "Kamusname" (Karasaev, 1996) and other considered to be special lexicographic works deeply rooted in their meaning. In the Kyrgyz language, the combination of words is very rare, because when two or more words are combined into complex words expressing the same meaning. This is because complex words written separately in spelling rules, while other complex words are combined or not.

Therefore, it can be said that complex words and phrases are developed in the Kyrgyz language. H. K. Karasaev collected such complex words, phraseologies and other complex expressions and wrote two chapter books called "Proverbs" (Karasaev, 1982). In these dictionaries, the meanings of words, the transitive meanings of phraseologies and the meanings of some phrases were interpreted, and most of them are given etymological analysis.

In addition, his work "Proverbs" which is not only interpreting the words meanings, but also provides a lot of ethnographic information and a broad understanding of these words. Many of these proverbs collected from the Kyrgyz people ancient life are forgotten and not used today. The profound psychological meanings reflected in such works have educational effect on the formation of each individual as a person. Thus, in the author's work "Kamusname" by Karasaev (1996) also carried out lexical, grammatical analysis of words, phrases, and lexical units learned from other languages.

\subsection{Other Works Contribution to the Kyrgyz Lexicography}

Another task of lexicography is not only to determine the meanings of words, but also to find out origin of words, from which language where they came from, and how they have undergone phonetic and semantic changes. A short etymological dictionary of the Kyrgyz language was developed in this direction (Seydakmatov, 1988). Unfortunately, this little book has been published with only a few word origins, but the fact that it lists the members of Qur'an at the end of the book, adds value to the work. In general, this work is the first dictionary of etymological research to explain the origin of words. It also helps future generations to understand the origins and etymology of proverbs, thereby forming a person's linguistic sensitivity, perception and thinking skills.

Creation and publication of Russian-Kyrgyz dictionaries play an important role in the development of Kyrgyz lexicography. The first such dictionary is mentioned above by H. Karasaev and after by the I.A. Batmanov's dictionary, the 25-chapter dictionary compiled by J. Shukurov and Y. Yanshansin was re- 
printed several times, and new editions were published in 1955, 1964, 1975, and 1988; in the Kyrgyz linguistics, a large number of dictionaries were written by $\mathrm{H}$. Karasaev, Zh. Shukurov and K.K. Yudakhin. These Russian-Kyrgyz dictionaries were later supplemented by several authors and contained fifty-one thousand words, published in 1957 by K.K. Yudakhin. A small Kyrgyz-Russian bilingual translation dictionary was developed by the famous linguist E. Abduldaev and published in 1994 (Musurmanova \& Sadirova, 2017: p. 13).

In the Kyrgyz lexicography, a newly developed Russian-Kyrgyz dictionary, which contained group of words was supplemented by scholars. P.I. Harahoz co-founded and announced; A. Osmonkulov and Zh. Mukambaev also developed a dictionary of words. Above works developed based on interpersonal linguists relation are establishing formation of the Kyrgyz people culture.

\subsection{Dictionaries in the Kyrgyz Lexicography}

Several thematic and explanatory dictionaries had been developed in Kyrgyz liguistics. In this regard, A. Biyaliev and N.L. Khmelnitskaya published a Russian-Kyrgyz dictionary of phraseology containing thematic lexicographic words in the Kyrgyz linguistics. This work includes phraseological, onomastic, homonymous, synonymous, antonymous dictionaries.

Kyrgyz lexicography includes not only bilingual but also trilingual translation dictionaries. The "Explanatory Dictionary of the Kyrgyz language" is also published in several editions. The first edition of this dictionary was edited in 1969 by famous lexicographers E. Abduldaev and D. Isaev. Developed by a team of several authors, this dictionary contains more than 20,000 words and considered as a great success of its time. The revised version of this dictionary is in two volumes, the first volume of which was published in 1986. Then it was supplemented by academician A. Akmataliev by several thousand new words, and in 2009 a large dictionary was published.

Translation dictionaries in Kyrgyz and other languages have been developed for a wide range of readers. Not only Kyrgyz-Russian, Russian-Kyrgyz, but also Kyrgyz-English, English-Kyrgyz, Kyrgyz-German, German-Kyrgyz, Kyrgyz-Uzbek, Uzbek-Kyrgyz, Kyrgyz-Dungan, Dungan-Kyrgyz dictionaries and conversations of various contents were developed. Such conversations establish psychological interpersonal relationships through nations.

\subsection{Dialects and Dialectical Words}

K. Yudahin emphasized great role of dialects and dialectisms in the addition of vocabulary. Important contributions to such works were made by V.M. Yunusaliev, G. Bakinova, Zh. Mukambaev, E. Abduldaev and others. The contribution of dialectologists is enormous, especially collected materials for the dialectological dictionary of the Kyrgyz language reflected as an appendix in M. Yunusaliev's textbook "Kyrgyz dialectology".

Well-known scientist-dialectologist Zh. Mukambaev collected tens thousands 
of dialectical words and published as a separate dialectological dictionary. The Kyrgyz dialectological dictionary was compiled by Zh. Mukambaev, a well-known linguist, who prepared seven volumes for publication, but only the first volume was published in 1972. The same first volume was revised and republished in 1976 (Abduvaliev, 2007: pp. 106-107).

Thus, the remaining volumes of dialectological dictionary were not published during the author's lifetime. Later, the full text of this book was published by Professor K. Konkobaev, initiated in 2002 by the Kyrgyz-Turkish Manas University.

\subsection{Encyclopedic Dictionaries Role}

Kyrgyz lexicography also published encyclopedic dictionaries, which was a great event in Kyrgyz culture. The Kyrgyz Soviet encyclopedia was published in six volumes from 1976 to 1980 . The first volume of encyclopedia was edited by A. Tabaldiev, the remaining five volumes were written and published by academician B. Oruzbaeva. Then encyclopedic dictionaries of each oblast, some districts, and encyclopedic dictionaries of agriculture and household were written as separate books.

In recent years, under the leadership of academician A. Akmataliev, the publication of encyclopedias “Toktogul Encyclopedia”, “Alykul Osmonov's Encyclopedia", "Sagymbai Encyclopedia”, "Sayakbai Encyclopedia" (Akmataliev, 2015), "Aitmatov's Encyclopedia" has become a major achievement in Kyrgyz lexicography.

He has written more than a hundred Kyrgyz-Russian and Russian-Kyrgyz terminological dictionaries in various fields of science, social and socio-psychological, economic fields, and has streamlined scientific and political-economic terminology. Especially in recent years, under the general editorship of academician A.A. Akmataliev of "Explanatory Dictionary of the Kyrgyz language" and the corresponding member of the Kyrgyz Republic S.J. Musaev were published capital works such as "Dictionary of words in the Kyrgyz language adopted from other languages" was a great innovation in the Kyrgyz lexicography.

Despite these achievements, it cannot be said that the lexical richness of the Kyrgyz language is one of the oldest languages among the Turkic languages, has been fully accumulated and all their meanings have been clarified. Because language is a social phenomenon that is constantly evolving and renewing, previous achievements in Kyrgyz language lexicography and history.

\subsection{K. Tynystanov's Works}

Kasym Tynystanov's works are a one more page in a Kyrgyz linguistics history (Koshueva, 2020: p. 607), which began to collect words and word group by phonetic structure, lexical and grammatical meanings, collected the history, mentality and folk knowledge of the Kyrgyz people. Study of their existence as archival materials and the work bring them to the attention of scientific community and 
considered as a valuable materials in the history of the Kyrgyz language.

As we have already mentioned, the achievements of the Kyrgyz language lexicography, the published translations, the materials of explanatory dictionaries reflect the lexical richness in the Kyrgyz language, mainly belonging to the Soviet period.

The words collected by K. Tynystanov, developed as a dictionary, should be in the lexical wealth that is still in the archives, mainly words from 1920-1930 and other lexical units. Thus, it should be borne in mind that Professor K. Tynystanov, who wrote the first textbooks in the Kyrgyz language and developed the first terminological dictionary, is at the forefront of the Kyrgyz linguistics lexicography.

\section{Conclusion}

In conclusion, since the main object of lexicography is the word, the addition of vocabulary of the Kyrgyz language has a special place. We paid special attention to the fact that professor K. Tynystanov worked on the words, the first terminological dictionary, taking into account the work of Kyrgyz scientists working in these fields.

It should be noted that his unpublished works on the collection of words stored in archival materials, the structural structure of words in the Kyrgyz language, lexical and grammatical meanings are of great importance for lexicographic purposes. A custom is determined by the level of development of a society, its culture. The study of folk culture begins precisely studied in the traditions and customs of the ethnos.

\section{Conflicts of Interest}

The authors declare no conflicts of interest regarding the publication of this paper.

\section{References}

Abduvaliev, I. (2007). Etymology and Lexicography (pp. 106-107). Bishkek.

Abildinova, Z. B. (2018). Linguistic Consciousness as a Psycholinguistic Phenomenon. Neophilology, 4, 33-43. https://doi.org/10.20310/2587-6953-2018-4-14-33-43

Akmataliev, A. (2015). Sagymbay Encyclopedia (1416 p). Bishkek.

Beisheev, T. B. (2018). Ethnocultural Aspects of Lexicography in the Development of Literature in the Kyrgyz School. Contemporary Higher Education: Innovative Aspects, 10, 94-100. https://doi.org/10.7442/2071-9620-2018-10-4-94-100

Chuvakhin, A. A. (2012). Applied Philology. Approximate Curriculum of the Academic Discipline (For the Profile “Applied Philology”). Philology and Man, No. 1, 178-182.

Dambuev, I. A. (2011). Modern Lexicography: Status and Directions of Development. Bulletin of the Buryat State University. Philosophy, No. 10, 16-21.

Karasaev, H. (1982). Proverbs: An Essay on Language (Book 1 and 2, 250 p). Kyrgyzstan.

Karasaev, H. (1996). Kamusname (Words from Arabic, Iranian, Chinese, Mongolian, Russian and Obsolete Words) (856 p). Sham. 
Koshueva, M. (2020). Contribution of the Founder of the Kyrgyz Lexicography K. Tynystanov to the Development of the Literary Language (on Archival Materials 1930-37). Bulletin of Science and Practice, 6, 604-609. https://doi.org/10.33619/2414-2948/52/73

Koshueva, M. Z. (2021). Borrowed Words in Kyrgyz Vocabulary. The Age of Science, No. 25, 206-210.

Koshueva, M., Abduvalieva, E., Yzabekova, D., Nadilbek Kyzy, B., Mamasadykov, A., Abduvaliev, I., \& Abdullaeva, Z. (2020). Phonetic Features of Sound-Copying Words Based on the Archival Materials. Open Journal of Modern Linguistics, 10, 665-674. https://doi.org/10.4236/ojml.2020.106041

Leontieva, T. V. (2014). Rus. Custom and Its Synonyms as an Object of Linguistic Study. Scientific Dialogue, Philology. Pedagogy, 9, 37-57.

Maslova, V. A. (2018). The Main Trends and Principles of Modern Linguistics. Rusistika, 16, 172-190. https://doi.org/10.22363/2313-2264-2018-16-2-172-190

Musurmanova, G. S., \& Sadirova, K. (2017). Linguistic Dictionaries of the Kyrgyz Language. Territory of Science, No. 1, 12-16.

Rakhimova, D. F. (2014). Concept: Structural Analysis and Methods of Linguistic Research. Bulletin of Kazan Technological University, 17, 336-338.

Seydakmatov, K. (1988). Short Etymological Dictionary of Kyrgyz Language (336 p). Ilim.

Yudakhin, K. K. (1965). Kyrgyz Russian Dictionary (p. 11). Soviet Encyclopedia. 